\title{
Migrantes, pós-colonialismo e fundamentalismo: enlaces entre Oriente e Ocidente e a questão do Islã
}

\author{
Soraya S. Smaili* \\ Universidade Federal de São Paulo. São Paulo, SP, Brasil
}

Resumo: Neste artigo foi abordado o enlace entre Oriente e Ocidente nas questões sociais e geopolíticas do século XX e início do XXI. Realiza-se uma breve análise sobre o colonialismo europeu e a sua construção considerando o mundo árabe e islâmico, os fluxos migratórios para os países centrais e a origem do fundamentalismo no Ocidente. As questões atuais se desdobram a partir da construção do orientalismo, da dominação política e econômica que levou à formação de estereótipos e preconceitos com o árabe e o islã. $O$ objetivo é apresentar elementos para uma reflexão a respeito da migração dos árabes e muçulmanos no contexto das guerras e conflitos do século XX e início deste século. Também visa esclarecer a origem dos estereótipos e reforçar a necessidade do conhecimento do outro para que o diálogo e a coexistência estejam no centro do debate.

Palavras-chave: migração, orientalismo, pós-colonialismo, fundamentalismo, cultura árabe-islâmica.

\section{Migrantes e o mundo em conflito}

A questão do exílio e do refúgio faz parte da história da humanidade. As causas do exílio, em grande parte, envolvem guerras, conflitos, perseguições diretas ou indiretas. Os fluxos migratórios e a busca de refúgio ocorrem como consequência desses fatores, como forma de proteção, acolhimento ou sobrevivência. Entretanto, se as causas são diversas, as histórias de adaptação e conflitos do presente e passado nem sempre são diferentes. Verifica-se, na maioria dos casos, as dificuldades advindas do encontro de gerações ou de culturas que podem levar a conflitos de ordem racial, social ou geracional.

No século XX a questão do refúgio tomou contornos mais abrangentes, que se apresentam ao longo de todo o período devido à ocorrência de duas grandes guerras que atingiram brutal e mundialmente a humanidade. O século também é marcado pelo colonialismo moderno e pelos efeitos do pós-colonialismo e dos pós-guerras. As ações que produzem grandes movimentações humanas são muitas, algumas delas organizadas, outras não. É devido a essas movimentações, facilitadas pelo desenvolvimento tecnológico que facilita o traslado e a mobilização das pessoas, que ocorrem encontros entre culturas e tradições que nunca haviam se deparado. É também no século XX que a questão do orientalismo, ou seja, a leitura do Ocidente em relação ao Oriente, passa por análises políticas, por vezes carregadas de interesses objetivos e subjetivos. As consequências no final do século são notórias e apresentadas como um conjunto grande de contradições. Ao mesmo tempo em que se tem mais mobilidade, tem-se também muita segregação. Quanto mais o encontro entre as tradições e a diversidade acontece, mais ocorrem discriminações e

* Autora correspondente: ssmaili@unifesp.br xenofobia. Quanto maior o acesso à tecnologia e à informação em larga escala, maior a alienação e a aculturação.

Se as grandes movimentações humanas trazem a questão do refúgio, também trazem a da busca por um novo lugar. Esse lugar se consolida no cotidiano daquele que se encontra permanentemente, ou a maior parte do tempo, "fora de lugar". Essa condição coloca a necessidade de se criar uma nova história, personalidade e trajetória a partir da nova vida, mas agrava o sentimento do exílio forçado (Said, 2004).

Muitas questões subjetivas estão relacionadas à condição do "fora de lugar", o que inclui as questões políticas, geográficas e de território. Na última década do século XX, muitas mudanças estavam acontecendo no mundo como resultado da conturbada sequência das Grandes Guerras e da Guerra Fria. O fim do século é, portanto, marcado por análises como as realizadas por Fukuyama (1992), que profetizava que os grandes conflitos políticos do mundo teriam terminado com o fim da União Soviética e com a vitória do capitalismo e dos valores do Ocidente. Porém, logo em seguida, em uma espécie de contraposição, Huntington apresenta $O$ choque de civilizações (1997), com uma teoria em que o conceito predominante é que "as grandes divisões entre a humanidade e a fonte dominante de conflitos passaria a ser cultural" (p. 89). Nasce aqui a tese de que os conflitos não seriam mais de ordem econômica ou social, e sim de ordem cultural, especialmente entre o Ocidente e o Oriente, o último com suas tradições frequentemente apresentadas como retrógradas e pouco civilizadas. $\mathrm{O}$ fim do século XX parecia, portanto, bem preparado para o suposto conflito de culturas que viria a seguir.

Coincidentemente, é logo no início do século XXI que ocorre $\mathrm{o}$ ataque às Torres Gêmeas em 11 de setembro de 2001, onde a teoria do choque de civilizações é utilizada para analisar e frequentemente explicar a realidade. Assim, os fatos e a história que se sucederam aos horrores 
do acontecimento são exaustivamente usados para apontar que o Oriente, em particular o Oriente Médio, estaria declarando guerra ao Ocidente. A visão de que este mesmo Oriente (em particular os países árabes) eram responsáveis pelo terror e por ações de violência passa a ser a visão mais disseminada no mundo globalizado. Em pouco tempo a visão de que os países do Oriente Médio abrigam a ignorância e o ódio foi transmitida e espalhada, o que justificaria que eles fossem indiscriminadamente ocupados e dominados.

Dessa forma, as culturas milenares e as tradições do Oriente são relativizadas e reduzidas, sendo o mote principal das diferenças a religião, em especial as diferenças entre as religiões mais presentes no Ocidente e o islã. Torna-se forte, embora não comece aqui, a visão estereotipada do árabe e do muçulmano, e torna-se artificialmente dramática a diferença entre o que seria civilizado e o que seria incivilizado, entre o que é desenvolvido e o que não é desenvolvido, entre o que é certo e o que é errado. As distorções são alimentadas e amplificadas por um desconhecimento profundo do Ocidente sobre o Oriente, sobre seus povos e culturas, o que cria um distanciamento cada vez maior, apesar do acesso cada vez maior às tecnologias e à velocidade de informações presente no mundo contemporâneo. O Oriente Médio e os árabes, passam a ser associados a povos distantes, pouco civilizados, pouco ou nada cultos, em que a maioria das pessoas professa uma religião estranha aos costumes do Ocidente. Criam-se condições perfeitas para a teoria e o exercício do "choque de civilizações". As correntes hegemônicas e as informações distribuídas pelos grandes meios de comunicação, dominados essencialmente pelos países centrais, ignoram a base das questões de ordem geopolítica. É necessário que estes elementos, especialmente os relativos aos recursos energéticos e interesses econômicos na região, sejam considerados e analisados. A matriz energética do mundo foi constituída e baseada na extração e utilização de recursos naturais não renováveis, em especial o petróleo e o gás natural, cujas maiores fontes estão exatamente no Oriente Médio. Portanto, precisa se considerar o interesse dos países mais dependentes destes recursos e a necessidade de dominar os países produtores, o que se coaduna com a escalada crescente de conflitos do Ocidente com o Oriente. Este ponto não será abordado neste artigo, mas pode ser revisto nos trabalhos de Fuser (2008) e de Olic e Caneppa (2012).

Neste contexto do mundo globalizado e dos supostos conflitos culturais entre Oriente e Ocidente, dos interesses geopolíticos no Oriente Médio, do crescimento do fundamentalismo de todas as ordens e da exacerbação dos estereótipos, refúgio e exílio tornaram-se questões prementes, mas fatores críticos do contemporâneo.

\section{Orientalismo: uma obra à frente do seu tempo}

O século XX foi permeado de situações que anunciavam a discriminação com a cultura árabe e o oriente, tornada natural em um modo hegemônico de conceber a vida em sociedade. A construção mais complexa desse cenário se deve a vários fatores, tais como as consequências do pós-colonialismo europeu. O interesse geopolítico parece plausível, já que o Oriente Médio abriga países não árabes muçulmanos (como o Irã e o Afeganistão) que também possuem reservas naturais. Uma análise mais aprofundada mostra, de fato, que a teoria do choque de civilizações torna-se simplista e pouco plausível, como mostrou Ali (2002) em seu livro Confronto de Fundamentalismos e mais recentemente o professor e pesquisador Aslan em Beyond Fundamentalism (2010), citando apenas alguns.

Especial atenção deve ser dada ao extenso trabalho de Said (2007), que demonstrou histórica, social e antropologicamente a formulação do orientalismo inicialmente em 1978, editado várias vezes em diversos idiomas. Em seu livro, muito à frente do nosso tempo, Said previu o que se construiria nas décadas seguintes, pois evidenciava que durante a década de 1970 ocorreria a crise mundial do petróleo e a Guerra dos Seis Dias. Nos anos subsequentes, o mundo assistiu à teoria se tornar realidade e ser ampliada pelo poder da grande mídia mundial, que contribuiu para deteriorar ainda mais a imagem do árabe, alimentando e reforçando os estereótipos. O papel da mídia na aplicação da tese orientalista foi evidenciado claramente no trabalho de Castro (2007), inclusive no Brasil. Além da imprensa, devem ser destacadas as distorções criadas também pela indústria do cinema estadunidense, em especial por Hollywood, abordadas e analisadas no livro Reel bad arabs: How Hollywood vilifies a people (Shaheen, 2009), que foi ilustrado de forma interessante em um documentário com o mesmo título. O livro, que deu origem a um documentário, mostra claramente como ao longo de várias décadas o cinema dos EUA apresentou a mulher árabe como prostituta e o homem árabe como idiota, ladrão ou bandido. Mais recentemente, tem sido retratado como violento, ignorante e, em especial, como terrorista. Felizmente, o cinema árabe, tão antigo quanto o cinema americano, iniciado no Egito, tem dado demonstrações e apresentado produções de extrema importância para a compreensão do árabe e a dissolução dos estereótipos. No Brasil, estes filmes passaram a ser exibidos na Mostra Mundo Árabe de Cinema, organizada pelo Instituto da Cultura Árabe.

\section{Tradição, pós-colonialismo e o mito do fundamentalismo}

Como se não bastassem todas as distorções em relação aos árabes, o Ocidente tratou de criar grande desinformação a respeito do islã, que é a religião professada pela ampla maioria da população dos países do norte da África, do Oriente Médio e boa parte da Ásia (não árabe). Atualmente a população dos países árabes é de 300 milhões, entre muçulmanos, cristãos e outros, enquanto a população muçulmana chega a 1,4 bilhão. No entanto, a discriminação e os estereótipos atingem a todos, mais especialmente aos muçulmanos árabes. Além disso, existe uma dificuldade das sociedades do Ocidente em separar tradições e cultura 
de religião, ou mesmo de política. O filme Incêndios (2010), do diretor Villeneuve, demonstra essa hipótese, já que o cenário remete à Guerra Civil Libanesa, ocorrida entre 1975 e 1990. Ela foi cunhada erroneamente como uma guerra entre cristãos e muçulmanos, mas se tratava de uma guerra de posições políticas e partidárias, já que os partidos se organizam de forma confessional no país. O sectarismo advém dessa divisão política, e não propriamente da religiosa, o que se mistura também com as tradições locais. Muitas vezes as tradições de cristãos e muçulmanos se enlaçam, pois pertencem ao mesmo grupo étnico e seguem costumes e tradições tão semelhantes que é difícil distingui-los. No filme verifica-se que a violência e $o$ ato de terrorismo contra civis não se inicia com a facção muçulmana, contrariando as expectativas e evidenciando o fundamentalismo como prática fascista de imposição do poder, que não é atributo de uma determinada religião. De fato, o fundamentalismo como concepção tem sido amplamente estudado por diversos autores. Foi essencialmente Armstrong (2001), entretanto, que apresentou evidências de que a origem do fundamentalismo encontra-se nas religiões protestantes dos EUA, presente também no judaísmo e islamismo. Curiosamente, no filme Incêndios, a protagonista, que é cristã e é expulsa da família por engravidar antes do casamento, acaba se revoltando com sua própria origem e se transforma em uma combatente do lado muçulmano, mostrando que a questão religiosa não é determinante, mas sim a questão política. $\mathrm{O}$ filme também mostra que as tradições seculares, tais como a família, a mulher e o sistema patriarcal, envolvem tanto cristãos quanto muçulmanos e estão enraizadas na construção daquelas sociedades, independente da religião. De fato, a força da tradição se sobrepõe às questões religiosas.

\section{0 orientalismo do século XXI e 0 muçulmano como o não eu}

Como mencionado anteriormente, o século XX trouxe profundas modificações na geopolítica dos países do Oriente Médio. O mundo árabe, que compreendia um território amplo, era unificado pelo mesmo idioma, embora tenha abrigado diferenças regionais já que a ampla maioria foi arabizada com o advento do islã a partir do século VII. Embora fosse bastante diversificado nas diferentes regiões e culturas locais, o mundo árabe foi objeto de divisões coloniais que marcaram profundamente sua história. A partir do Tratado de Sykes-Picot, uma parte do Oriente Médio e o Norte da África, também chamado de Maghreb, foram divididos entre França e Inglaterra, que partilharam os últimos legados do Império Otomano. As fronteiras foram traçadas de maneira arbitrária e sem levar em consideração as questões regionais, sociais e culturais de cada local e região, o que fez com que grupos étnicos diferentes iniciassem conflitos entre si e com os próprios colonizadores. Com o fim da era colonial e depois da Segunda Guerra Mundial vieram os conflitos internos e as ditaduras sustentadas pelos países centrais, que tinham interesse em controlar a região devido à sua matriz energética.
O que pouco se divulga é que o advento do islã a partir do século VII trouxe à península Arábica, e às regiões por onde se expandiu, enorme desenvolvimento científico e tecnológico por mais de oito séculos, possibilitando uma expansão e crescimento territorial de enormes proporções. A história detalhada de todo o período pode ser mais bem avaliada no livro Uma história dos povos árabes (Hourani, 2006). Após oito séculos de crescimento e nos séculos subsequentes relativos à ascensão e decadência do império turco-otomano, a Europa equaliza suas necessidades de expansão em direção aos países árabes. Já no século $\mathrm{XX}$, com o conhecimento acerca das matrizes energéticas desses países, ocorre o acordo de Sykes-Picot, que leva a uma divisão colonial do mundo árabe. Paralelamente a isso ocorrem as Grandes Guerras. Após o colonialismo francês e britânico sucedem-se as ditaduras violentas e, em muitos casos, corruptas. Guerras localizadas ocorrem em regiões que vivem sob forte opressão dos regimes autoritários, além de empobrecimento econômico e perda de direitos sociais. Como resultado, são observados diversos fluxos migratórios, em especial do Maghreb para a França e Inglaterra e dos países do Oriente Médio para vários pontos da Europa e das Américas. Esse enorme contingente de imigrantes, na sua maioria de muçulmanos, encontra diferenças nos acolhimentos. Nos países americanos são considerados uma nova força de trabalho, mas na Europa e nos EUA tornam-se, em geral, uma segunda ou terceira classe social, e encontrarão a segregação e a marginalização e pouca integração. Apesar disso, os países do eixo Norte-Norte adentram o século XXI com um enorme contingente de exilados, voluntários ou não, que buscam refúgio, trabalho e proteção. Ao mesmo tempo em que esses fluxos de imigração acontecem, ocorrem também sérias questões sociais que se transformam em campo fértil para o crescimento do fundamentalismo associado a algum movimento islâmico de origem obscura e incerta. Em contexto de agravamento das questões sociais e econômicas imbricado à falta de oportunidades no novo mundo, as correntes fundamentalistas ditas islâmicas tornam-se uma opção tanto para os jovens dos países pós-colonizados como para os imigrantes e descendentes marginalizados pela sociedade.

O caso da Europa, em particular da França, deve ser destacado e analisado como tem sido feito por diversos historiadores e sociólogos (Lacoste, 2006), que evidenciam com clareza os resultados da dominação colonial francesa na Argélia, oprimindo-a e empobrecendo-a, além de ter promovido grandes revoltas e perdas econômicas e sociais que resultaram em uma revolução pela libertação. Ao término deste período, a França recebeu um enorme fluxo migratório de jovens argelinos, inicialmente aceitos como força de trabalho, cidadãos de segunda categoria levados a realizar o trabalho que os jovens franceses não desejavam. O crescimento e a falta de inserção social dos filhos e netos desses imigrantes produziu movimentos de revolta política instrumentados pelos ritos de grupos religiosos que alimentaram uma alternativa de engajamento e de suposta aceitação por um grupo (Cohen, 2012). A ausência de oportunidades de 
emprego, de educação e uma crise identitária promoveu uma alienação e uma dissociação social alimentada pelo ódio e revolta. Por outro lado, evidenciou-se a reação da sociedade francesa e o crescimento dos movimentos nacionalistas e xenófobos (ver também Blanchard, Bancel, \& Lemaire, 2005).

Embora os grupos mais alienados e fundamentalistas sejam minoritários e a grande maioria dos muçulmanos cultive e busque a integração, o que se observou foi a produção de estereótipos generalizados, com maior discriminação e alienação. Existe, portanto, um forte desejo de assimilação e uma contraposição à alienação (Ramadan, 2010). O trágico e inadmissível assassinato dos cartunistas do Charlie Hebdo no início de 2015 trouxe novamente estas questões a respeito da imigração argelina na França, bem como as questões sociais e o crescimento do nacionalismo europeu. Traz também o recrudescimento dos estereótipos em relação ao islã e muita adesão aos movimentos de intolerância. Em contrapartida, verifica-se que os votos da extrema direita se concentram justamente nos lugares com o maior número de argelinos e descendentes. "As pessoas que vivem perto da população de origem magrebina são as que mais votam no FN", diz Alidières (2011). Esse cenário nos conclama a uma reflexão mais elaborada e representativa da realidade. Como afirma a historiadora Pitti (2010), especialista em imigração argelina e membro da equipe que trabalha no futuro Museu da Imigração em Paris, "o background das tensões atuais é a crise econômica da França, a maneira de o governo reagir a ela e também a intensificação de uma série de estereótipos contra imigrantes argelinos, criados na época colonial". Segundo Cohen (2012), essa ideia ampliouse com o tempo, os preconceitos aumentaram e o medo de muçulmanos cresceu. A segregação torna-se uma disposição específica na lei de imigração que faz referência aos argelinos. $\mathrm{O}$ efeito do terrorismo é enorme sobre esse confronto social, principalmente depois do 11 de Setembro nos EUA e dos ataques em Londres e Madri, o que amplifica o preconceito. Segundo dados oficiais a França tem aproximadamente 6 milhões de imigrantes de origem muçulmana, entre argelinos, tunisianos, marroquinos e africanos da região subsaariana e, desse total, 4 milhões têm nacionalidade estrangeira. A maioria contribui como força motora para o país, muitos trouxeram desenvolvimento econômico. Entretanto, o terror praticado por um grupo obscuro terá efeitos ainda mais avassaladores sobre o preconceito e a separação. Esse complexo de elementos sociais e políticos gerados pelas contradições trazidas também pelo pós-colonialismo apresentam desafios contemporâneos para a república e uma sociedade mais inclusiva (Cohen, 2012).

\section{A Cultura Árabe Islâmica e sua contribuição com a formação do Ocidente contemporâneo}

Um fato histórico concreto pouco lembrado atualmente é que os árabes existem há pelo menos 3500 anos e a civilização árabe contribuiu marcadamente em vários campos desde a origem da civilização. A sua contribuição para a civilização moderna e contemporânea intensificou-se a partir do século VII, com o surgimento do islã, época de grande expansão e aperfeiçoamento da língua árabe e da ampliação do conhecimento a partir do idioma. Por causa da expansão geográfica deste período, os árabes entraram em contato com diversas culturas como a grega, a hindu, a chinesa, a bizantina e a persa. A partir disso, passaram a conhecer os escritos e vertê-los para o árabe, aperfeiçoando-se na técnica de tradução e divulgação do conhecimento. Além disso, por conta da expansão territorial e por assimilarem prontamente outros saberes, realizam um grande processo de intercâmbios entre as diversas culturas. Tornam-se não só os grandes propagadores, mas os grandes catalisadores das transformações científicas que se seguiram aos anos de obscurantismo na Europa.

A partir do século VIII os primeiros califas abássidas estimularam o conhecimento de textos existentes a partir de traduções. Al Mansur foi o primeiro a financiar as traduções de obras científicas dos indianos e dos filósofos gregos antigos. Seus sucessores continuaram e ampliaram esta prática, o que levou à fundação da Casa do Saber, que acolhia os melhores sábios da época e tornava-se o primeiro centro científico que inspiraria posteriormente as primeiras universidades europeias. Entre os manuscritos traduzidos e guardados pelos árabes estavam textos desaparecidos de Ptolomeu, Euclides, Galeno e tantos outros provenientes das ciências antigas que teriam sido destruídos durante a Idade Média, não fosse pela civilização islâmica.

$\mathrm{Na}$ atualidade, o muçulmano, como dissemos, é cada vez mais associado ao fundamentalismo, à violência e à ignorância, quando de fato estes são elementos totalmente alheios à tradição islâmica secular. O islã como filosofia e cultura civilizatória deve ser visto em acordo com sua origem, história e escrituras. No período em que a Europa viveu o obscurantismo da Idade Média, os tradutores, os filósofos e os estudiosos da época preservaram os manuscritos do mundo antigo e os dos cientistas perseguidos pela igreja católica e pela inquisição. No período seguinte, observa-se um amplo período de criação e desenvolvimento nas ciências, artes, literatura e medicina, óptica, mecânica, física, matemática, arquitetura, música e tantas outras maravilhas realizadas por esta que foi chamada de civilização árabe-islâmica (Djebbar, 2005). Um grande avanço também é observado na elaboração dos códigos éticos, na construção de normas e leis que promovem uma riqueza na construção das relações sociais, de sofisticados códigos de convivência. Esse conjunto evidencia o exercício natural da coexistência em conceito mais abrangente do que o da simples tolerância. A coexistência do período islâmico na Europa atinge o seu auge com a constituição do $\mathrm{Al}$ Andalus, onde árabes, judeus e cristãos convivem, trocam tradições e acolhem mutuamente suas culturas, desenvolvendo o conceito de acolhimento, hospitalidade, cuidados com a saúde, bem estar e apreço pela sabedoria.

A partir do século IX e diante deste ambiente inicia-se o período emergente da ciência dos árabes. Neste momento os conhecimentos deixaram de ser adquiridos 
apenas a partir das traduções, passaram a ser aprimorados e novos saberes foram desenvolvidos e incorporados. Entre os séculos X e XIII acontece o verdadeiro apogeu da ciência árabe, e em Bagdá, além da Casa do Saber, é instalada uma das maiores bibliotecas da humanidade. Este ambiente de enorme estímulo intelectual prevaleceu e se ampliou, destacando-se pelas inúmeras descobertas na Matemática e Álgebra - com o desenvolvimento dos algarismos, do conceito de zero e do sistema decimal, da prática do cálculo, da álgebra, das equações trigonométricas e da aritmética. Dentre os grandes sábios destacam-se Al-Kwarismi (de onde vem a palavra algarismo), Ibn al-Haytam, al-Biruni entre outros tantos. Na Astronomia são recuperados os conhecimentos dos gregos antigos e desenvolvidas técnicas e instrumentos sofisticados de orientação (astrolábios e observatórios), determinação do tempo e modelos planetários. Na Geografia, conhecimento da geografia humana e cartografia. Na Física, desenvolvimento da hidrostática, da óptica, da mecânica. Na Arquitetura e artes decorativas, desenvolvimento de construções e elementos geométricos de grande sofisticação. Na Química, a partir de experimentos práticos, desenvolveram o sabão, elementos cosméticos como a água de rosas (a partir de técnicas de destilação) e do vinagre (a partir de técnicas de fermentação) devido a uma busca incessante pelo elixir da vida, do medicamento milagroso que poderia curar todos os males.

É interessante notar também os preceitos dos fundadores da doutrina. Tariq Ramadan, com base em estudos e evidências históricas, descreve a vida do profeta Mohamad em sua jornada (Ramadan, 2008), que é pouco conhecida pelo Ocidente. Os relatos mostram que Mohamad era um líder tolerante, gentil, honesto e atento às necessidades dos mais carentes e oprimidos. De fato, defende Ramadan, a vida e os exemplos dados apontam para os mais elevados preceitos e para o caminho da liberdade, da mensagem universal que transcende as divisões e as identidades étnicas.

\section{Imigrantes árabes e muçulmanos no Brasil}

A imigração árabe e a presença do islã no Brasil tem início antes mesmo da imigração mais recente. De fato, a influência islâmica começa a partir da vinda dos portugueses, que trazem consigo os oito séculos de influência decorrentes da presença árabe na península Ibérica. Os mouros, como eram chamados devido à cor morena de sua pele, sofreram com o obscurantismo religioso e intelectual e a perseguição, mas deixaram legados culturais e civilizatórios na Espanha e em Portugal. A presença islâmica promoveu a expansão da língua árabe, das ciências e do legado cultural e científico, que se torna fundamental diante do obscurantismo em que vivia a Europa da Idade Média. Segundo Houaiss (2001), a língua portuguesa daquele período não tinha a sofisticação da construção gramatical e vocabulário, e dependia muito mais do latim para a expressão de elementos mais complexos. O árabe era uma língua mais desenvolvida que o português, e deixou mais de $20 \%$ dos vocábulos e expressões que foram incorporados ao idioma que foi trazido pelos portugueses ao Brasil. Além disso, existem outras múltiplas influências mouras no legado social e antropológico português. Como relatou Ribeiro (2006) em O povo brasileiro - a matriz lusa, os portugueses puderam navegar e expandir seu império graças às embarcações e aos instrumentos de navegação desenvolvidos pelos árabes durante o período em que estiveram na península. Este e outros legados foram devidamente apagados pela narrativa hegemônica e eurocêntrica que sucedeu a dominação moura. Mais tarde o Brasil recebeu outra influência muçulmana, desta vez advinda de uma tribo africana aqui chamada de Malê, que era culta, desenvolvida e seguidora da religião islâmica. Chegaram ao Brasil como escravos, falavam e liam árabe e, por serem muçulmanos, conheciam a arte islâmica, a arquitetura e a caligrafia islâmica, que foram deixadas especialmente no nordeste do Brasil junto com a influência musical (Amrik, 2006).

O segundo movimento de influência árabe na construção da cultura brasileira foram os fluxos migratórios, que tiveram início há pouco mais de 130 anos. As razões para a vinda dos árabes ao Brasil são diversas. Truzzi (2009) salientou que esta imigração se diferenciou de outras imigrações da mesma época, pois foi marcada por fluxos migratórios contínuos a partir do final do século XIX. Foram árabes vindos principalmente da Síria e Líbano, que percorreram o século XX e atingiram o início do século XXI. Foram determinados por causas políticas, econômicas ou sociais já mencionadas anteriormente, em especial as guerras sectárias, as colonizações e o pós-guerra. No Brasil houve grande disseminação, devido à grande capacidade de mobilidade, de integração social, de convívio e de coexistência dos árabes. Nos últimos fluxos migratórios, especialmente a partir da década de 1950, chegam os árabes de origem muçulmana, que colaboraram para a construção social e econômica em larga escala. Os árabes influenciaram, de maneira integrada, diversos movimentos culturais, o que provavelmente contribuiu para a composição de uma identidade fluida e que se constrói a todo o momento e por toda vida, como salientaram em suas obras o escritor libanês Amin Maalouf e o intelectual mexicano Octavio Paz.

\section{Considerações finais: desconstrução de estereótipos por meio da arte e do conhecimento}

O presente trabalho apresentou elementos para reflexão sobre a migração dos árabes e muçulmanos no contexto das guerras e conflitos do século XX e início deste século. O mundo passou por grandes e rápidas transformações em algumas décadas, em especial no mundo árabe, passando pelo fim do império Otomano, o colonialismo europeu, a formação de novos países, os regimes ditatoriais e os grandes interesses dos países centrais por sua matriz energética. Os conflitos levaram a um grande fluxo migratório para países desenvolvidos ou em desenvolvimento. A busca do refúgio também levou a confrontos e a segregações que impulsionaram o crescimento da exclusão social e um desenvolvimento 
de movimentos neonacionalistas e xenófobos, em especial na Europa. Ao mesmo tempo houve uma rejeição ao não -europeu e a influências pertencentes a culturas diferentes. Reforçou-se a tese do orientalismo, descrita por Said (2007), onde o árabe é entendido como o outro, o não-europeu, e, portanto, excluído do universo eurocêntrico. Neste contexto, o fundamentalismo também é produto deste histórico e dos valores sociais, econômicos e políticos que fazem parte dele, já que a cultura milenar islâmica rejeita veementemente a intolerância e a ignorância em relação ao outro.

Neste início de século, a imagem e a cultura árabe foram fortemente estereotipadas, e distanciamentos entre as culturas devem ser observados para serem superados. $\mathrm{O}$ entendimento do outro como o eu, dos diferentes como semelhantes e próximos, pode e deve nos remeter à ideia da coexistência, do convívio e do diálogo que foi tão elaborado e preconizado pelo período do Andalus e, portanto, pela cultura islâmica. Iniciativas como a de Edward Said e Daniel Barenboim, que fundaram a Orquestra Diwan-Oriente Ocidente, devem ser maximizadas e ampliadas. Nesta iniciativa, o professor e o maestro criaram um ambiente para a educação musical de jovens árabes e judeus que convivem e coexistem, compreendendo suas limitações e suas histórias. Apesar da existência de um agravamento nos estereótipos, do paradoxo do sentimento do "fora do lugar", da não convivência e da aparente impossibilidade de coexistência, o momento requer uma ação vigorosa em direção à informação e educação sobre as questões econômicas, lutas pelo poder e interesses geopolíticos que levam aos conflitos e a guerra. É preciso buscar incessantemente o conhecimento do outro para a compreensão e respeito às culturas e à diversidade. Este é o desafio do nosso tempo, que deve ser assumido.

\title{
Migrants, post-colonialism and fundamentalism: links between East and West and the issue of Islam
}

\begin{abstract}
In this article, the link between East and West in social and geopolitical issues of the twentieth and early twenty-first centuries was approached. A brief analysis of European colonialism and its construction considering the Arab and Islamic world, migration to the central countries and the rise of orientalism was conducted. Current issues unfold from the construction of orientalism, the political and economic domination that led to the formation of stereotypes and prejudices towards the Arab and Islam. The goal is to provide elements for a reflection on the migration of Arabs and Muslims in the context of wars and conflicts of the twentieth century and beginning of this century. It also aims to clarify the origin of stereotypes and reinforce the need for knowledge of the other so that dialogue and coexistence are at the center of the debate.
\end{abstract}

Keywords: migration, orientalism, post-colonialism, fundamentalim, Arab-Islamic culture.

\section{Les Migrants, le postcolonialisme et le fondamentalisme: liens entre l'Orient et l'Occident et la question du Islam}

Résumé: Dans cet article, on fait une approche des questions telles que le lien entre l' Orient et l'Occident en ce qui concerne les problèmes sociaux et géopolitiques du XXe siècle et au début du XXle siècle. Dans une brève analyse on présent de certaines questions fondamentales du colonialisme européen et sa construction en lien avec le monde arabe et islamique, la migration vers les pays de base et la montée du fondamentalisme dans l'Occident. Les conflits actuels ont été développés à partir de la construction de l'orientalisme, de la domination politique et économique qui a conduit à la formation des stéréotypes et des préjugés envers l'arabe et l'islam. La situation conflictuelle aujourd'hui est fondé sur les intérêts géopolitiques et économiques, beaucoup plus que les différences culturelles ou religieuses. L'article vise à clarifier certains des stéréotypes, en indiquant des liens possibles, et à renforcer la nécessité d'une connaissance de l'autre pour mettre le dialogue et la coexistence au centre du débat.

Mots-clés: migration, orientalisme, postcolonialisme, fondamentalisme, culture arabo-islamique.

\section{Migrantes, poscolonialismo y fundamentalismo: enlaces entre el Oriente y Occidente y la cuestión del Islam}

Resumen: En este artículo se abordó el enlace entre Oriente y Occidente en las cuestiones sociales y geopolíticas del siglo XX y principios del XXI. Se realizó un breve análisis acerca del colonialismo europeo y su construcción considerando el mundo árabe e islámico, los flujos migratorios para los países centrales y la origen del fundamentalismo en el Occidente. Las cuestiones actuales se desdoblan a partir de la construcción del orientalismo, de la dominación política y económica que llevó a la formación de estereotipos y prejuicios hacia el árabe y el islam. El objetivo es la presentación de elementos para la reflexión acerca de la migración de los árabes y musulmanes en el contexto de guerras y conflictos del siglo XX y principios de este siglo. También tiene por objetivo aclarar la origen de los estereotipos y reforzar la necesidad del conocimiento del otro para que el diálogo y la coexistencia estén en el centro del debate.

Palabras clave: migración, orientalismo, poscolonialismo, fundamentalismo, cultura árabe-islámica. 


\section{Referências}

Ali, T. (2002). Confronto de fundamentalismos. Rio de Janeiro, RJ: Editora Record.

Alidières, B. (2011). Un renouveau du vote Front national? In: Institut Français de Géopolitique, Revue Hérodote Université Paris 8.

Amrik - Mostra sobre a presença árabe na América do Sul (2006). Realizada em Brasília e São Paulo: Ministério das Relações Exteriores e Instituto da Cultura Árabe.

Armstrong, K. (2001). Em nome de Deus: o fundamentalismo no judaísmo, no cristianismo e no islamismo. São Paulo, SP: Companhia das Letras.

Aslan, R. (2010). Beyond fundamentalism: confronting religious extremism in the age of globalization. USA: Random House.

Blanchard, P., Bancel, N., \& Lemaire, S. (2005). La fracture coloniale. Paris: La Découverte.

Castro, I. C. S. (2007). Orientalismo na imprensa brasileira. A representação de árabes e muçulmanos nos jornais 'Folha de São Paulo' e 'O Estado de São Paulo' antes e depois de 11 de setembro de 2001 (Dissertação de Mestrado). Faculdade de Filosofia, Letras e Ciências Humanas, Universidade de São Paulo, SP.

Cohen, J. (2012). Postcolonial immigrants in France and their descendants: The meanings of France's 'Postcolonial Moment'. In U. Bosma, J. Lucassen \& G. Oostindie (Orgs.), Postcolonial migrants and identity politics: Europe, Russia, Japan and the United States in comparison. Oxford, NY: Berghahn Books.

Djebbar, A. (2005). L'age D’or des Science arabe. Paris: Le Pommier.

Fukuyama, F. (1992). O fim da história e o último homem. São Paulo, SP: Rocco.

Fuser, I. (2008). Petróleo e poder. São Paulo, SP: UNESP.
Houaiss, A. (2001). Grande dicionário Houaiss. Rio de Janeiro, RJ: Objetiva.

Hourani, A. (2006). Uma história dos povos árabes São Paulo, SP: Companhia de Bolso.

Huntington, S. (1997). Choque de civilizações. Rio de Janeiro, RJ: Objetiva.

Instituto da Cultura Árabe. (2004). Mostra Mundo Árabe de Cinema. Recuperado de http://icarabe.org/mostras-decinema-do-icarabe

Lacoste, Y. (2006). The postcolonial question. Hérodote, n. 120,272 p.

Olic, N. B., \& Caneppa, B. (2012). Oriente Médio. São Paulo, SP: Moderna.

Pitti, L. (2010). Memoires du travail à Paris. Paris: CREAPHIS.

Ramadan, T. (2009). The messenger, the meanings of the life of Muhammad. Hardcover,

Ribeiro, D. (2006). O povo brasileiro. A formação e o sentido do Brasil. São Paulo, SP: Companhia de Bolso.

Said, E. (2007). Orientalismo. São Paulo, SP: Companhia de Bolso.

Said, E. (2004). Fora do lugar: memórias. São Paulo, SP: Companhia das Letras.

Shaheen, J. (2009). Reel bad Arabs. How Hollywood vilifies a people. EUA: Interlink Books.

Truzzi, O. (2009). Patrícios: sírios e libaneses em São Paulo (2a ed.). São Paulo, SP: Ed. da UNESP.

Villeneuve, D. (2010) Incêndios (filme) 